\title{
Karyomorphological Studies in Chlorophytum Ker-Gawl.
}

\author{
V. P. Patil, M. S. Kumbhojkar and S. S. Gandhi \\ Department of Genetics, \\ M.A.C.S. Research Institute, Pune 411 004, India
}

Accepted July 18, 1986

The genus Chlorophytum Ker-Gawl. belongs to the tribe Anthericineae of sub-family Asphodeleae of Liliaceae (Engler and Prantl 1930). It comprises of about 234 species distributed in the tropical and sub-tropical regions, majority being in Africa. In India, fifteen species have been described so far (Hooker 1892, Santapau and Fernandes 1955). This genus has been studied in detail from cyto-taxonomic and cytogeographic points of view by Pahuja and Kumar (1969), Baldwin and Speese (1951), Sheriff $(1967,1971)$, Sheriff and Chennaveeraiah (1975), Mukherjee (1975), Naik (1977) and others. These studies reveal the existence of two basic chromosome numbers of 7 and 8 in this genus and the role of polyploidy in the speciation processes. Hence, an attempt has been made to detect the relationships based on chromosome number and morphology of six species of Chlorophytum Ker-Gawl.

\section{Materials and methods}

During monsoon, live plants of the following species have been collected and planted in the MACS nursery:

Species

C. laxum R. Br.

C. tuberosum Baker

C. attenuatum Baker

C. comosum Jacques

C. orchidastrum Lindl.

C. glaucum Dalz.
Locations

around Poona

Poona University Campus

Konkan region

Garden plant

Purandhar Fort

Bhimashankar

Root tips have been collected from the potted plants at 9.30 am, and pretreated with $\alpha$ bromonaphthalene for two hours at $4^{\circ} \mathrm{C}$. Slides are prepared according to the procedure of Sharma and Mookherjea (1955). Camera lucida drawings have been sketched at bench level. Numerical sequence of individual chromosomes in the complement is given according to the criteria adopted by Sears (1958) and Riley (1963). Karyotype symmetry has been analysed using Stebbins' (1958) system of classification based on relative arm-lengths and arm-ratios.

\section{Results}

Quantitative data on mean total chromosomal length of haploid complement, graded armratios have been summarized in Table 1. Idiograms and photomicrographs of somatic metaphase plates of these species are presented in Plates 1 and 2.

It is evident from the table that in $C$. laxum, C. tuberosum and $C$. attenuatum the chromosome number observed is $2 \mathrm{n}=16$, in $C$. comosum it is $2 \mathrm{n}=28$ and in $C$. glaucum and $C$. orchidastrum it is $2 \mathrm{n}=42$. Total chromosome length of the haploid complement is maximum in the last two species and minimum in the species with $2 n=16$. Ratio of longest/shortest chromosomes appears to be minimum in $2 n=16$, intermediate in $2 n=28$ and maximum in $2 n=42$. This suggests roughly the extent of deviations in individual chromosome lengths, maximum 


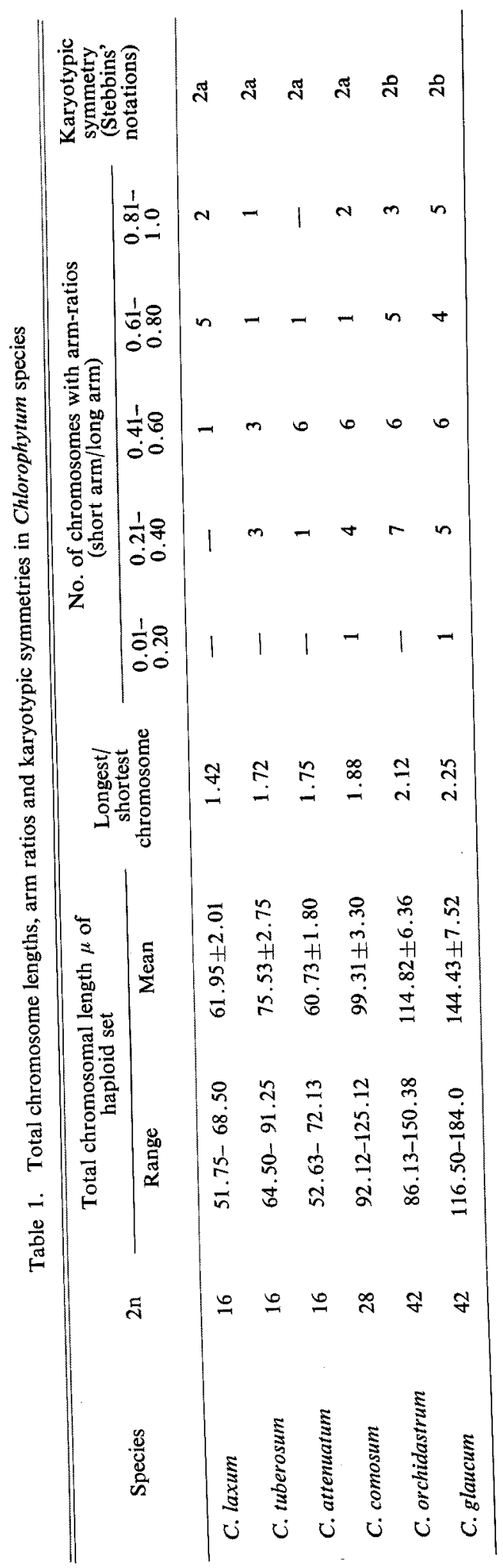


being in glaucum and orchidastrum and minimum in laxum. Number of chromosomes with median centromeres appears to be higher in C. glaucum and C. orchidastrum. Among the species with $2 \mathrm{n}=16$, such chromosomes are relatively more in C. laxum (Plate 1). Chromosomes with

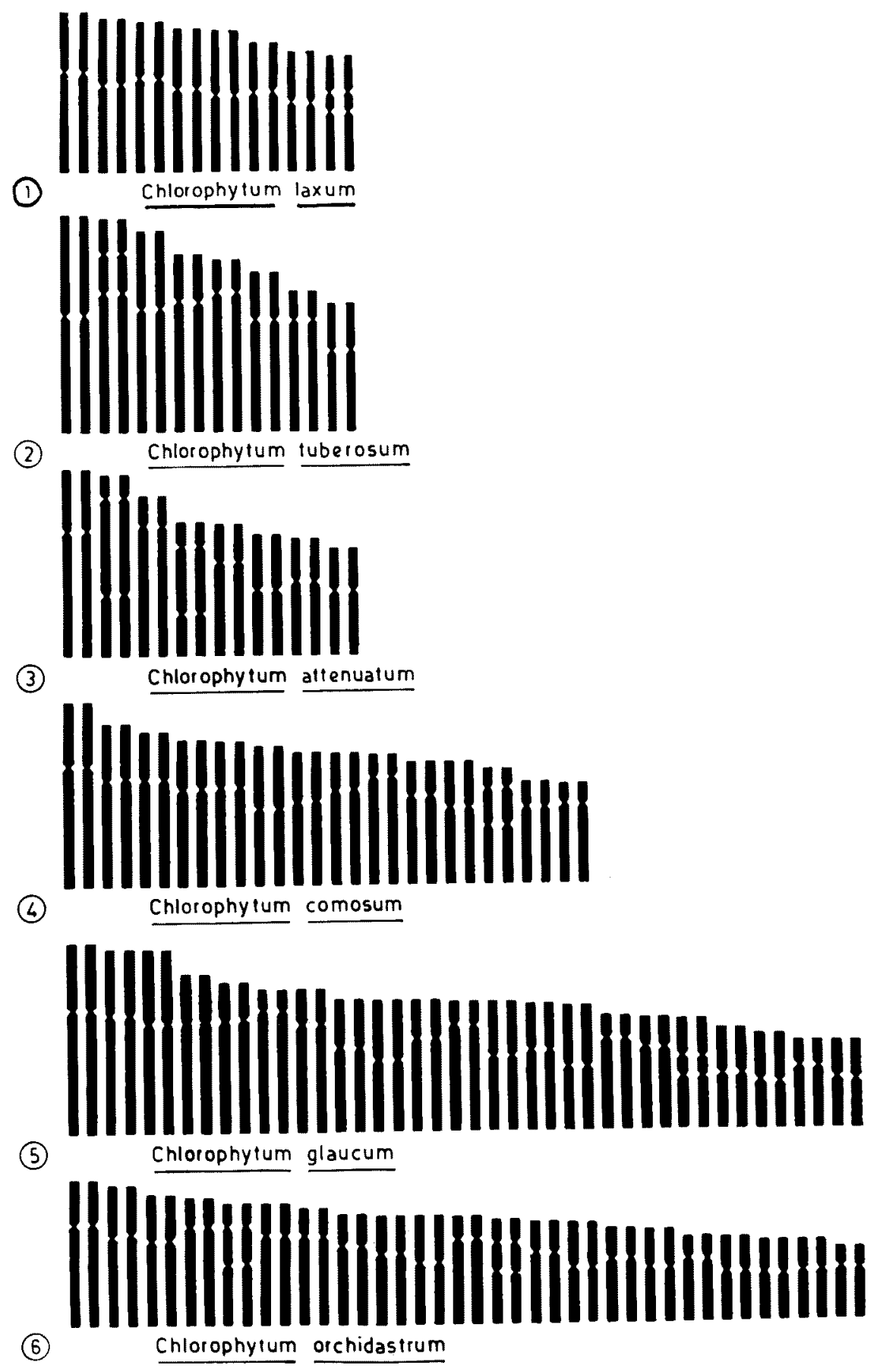

Plate 1. Idiograms of (1) C. laxum, (2) C. tuberosum, (3) C. attenuatum, (4) C. comosum, (5) C. glaucum and (6) C. orchidastrum 
subterminal centromeres are also relatively more in number, in orchidastrum, glaucum and comosum. By using Stebbins' notations (1958), C. glaucum and C. orchidastrum appear to have relatively more differences as these species belong to $2 \mathrm{~b}$ grade. Further details on karyotype asymmetries are given in Table 2.

The difference between longest and shortest chromosomes (L-S) is maximum in glaucum and minimum in laxum. Similar trends are observed for number of heterobrachial chromosomes. Coefficient of variability for chromosome length appears to be least in laxum.

Among the six Chlorophytum species studied, only in attenuatum and orchidastrum there are two pairs of SAT chromosomes, whereas in rest of the species one pair may be observed (Table 3, Plates 1, 2). SAT chromosome is one of the longest chromosomes in tuberosum and attenuatum (sequence No. II). Similarly, in comosum and orchidastrum the sequence number is XII. In other species sequence number varies in the complement. It is also interesting to note that the SAT chromosomes with same sequence number have closer arm ratios (S/L). For SAT 2, it is clearly seen that the arm ratios for laxum, attenuatum, orchidastrum and glaucum are more or less similar. In all these species SAT-knob is attached to the short atm of the chromosome except for attenuatum where both the SAT chromosomes indicate SAT-knob being attached to the long arms (see idiograms).

Table 2. Karyotypic asymmetries in Chlorophytum species

\begin{tabular}{|c|c|c|c|c|c|c|c|}
\hline \multirow{3}{*}{ Species } & \multirow{3}{*}{$\begin{array}{c}\text { Longest } \\
\text { chromosome } \\
\mathrm{L} \\
\mu\end{array}$} & \multirow{3}{*}{$\begin{array}{c}\text { Shortest } \\
\text { chromosome } \\
\text { S } \\
\mu\end{array}$} & \multirow{3}{*}{$\begin{array}{c}\text { Difference } \\
\text { L-S } \\
\mu\end{array}$} & \multicolumn{3}{|c|}{ No. of chromosomes } & \multirow{3}{*}{$\begin{array}{c}\text { Coeff. of } \\
\text { varia- } \\
\text { bility } \\
\text { for } \\
\text { length }\end{array}$} \\
\hline & & & & \multirow{2}{*}{$\begin{array}{l}\text { Homobra- } \\
\text { chial }\end{array}$} & \multicolumn{2}{|c|}{ Heterobrachial } & \\
\hline & & & & & SMC & STC & \\
\hline C. laxum & $8.78 \pm 0.28$ & $6.20 \pm 0.31$ & 2.58 & 1 & 7 & - & 0.1325 \\
\hline C. tubersoum & $11.63 \pm 0.95$ & $6.75 \pm 1.69$ & 4.88 & - & 5 & 3 & 0.1828 \\
\hline C. attenuatum & $9.96 \pm 0.10$ & $5.69 \pm 0.08$ & 4.27 & - & 8 & - & 0.1875 \\
\hline C. comosum & $9.79 \pm 0.32$ & $5.22 \pm 0.19$ & 4.57 & 1 & 8 & 5 & 0.1670 \\
\hline C. orchidastrum & $7.64 \pm 0.13$ & $3.60 \pm 0.07$ & 4.04 & 2 & 19 & 一 & 0.1907 \\
\hline C. glaucum & $10.00 \pm 1.41$ & $4.45 \pm 0.17$ & 5.55 & 1 & 14 & 6 & 0.2043 \\
\hline
\end{tabular}

SMC-sub-median chromosomes

STC-sub-terminal chromosomes

Discussion

Karyomorphology and symmetry

Present observations on the karyomorphology of six Chlorophytum species clearly suggest the chromosomes with median or submedian centromeres to be more in C. laxum. This is also supported by relatively less values for longest/shortest chromosome ratio. This ratio appears to be highest in C. glaucum (Table 1). Broad estimation of karyotype symmetry also corroborates the same. Even the coefficient of variablility of individual chromosomes in the complement (calculated by processing length deviations of individual chromosomes over mean length of the respective complement) also fortifies these observations.

Presence of secondary constrictions has been reported in C. comosum, C. attenuatum, $C$. malabaricum and other species by Sheriff (1967), Sheriff and Chennaveeraiah (1975) and Naik (1977), though in the present studies such situations could not be noted. This might have been due to the possibility of existence of different biotypes under the same species or the observational errors.

SAT chromosomes observed in these six species vary in their sequence numbers as also in the arm-ratios. In $C$. tuberosum and $C$. attenuatum one of the longest chromosomes (sequence number II) is the SAT chromosome and the SAT-knob is attached to the longth arm in attenu- 


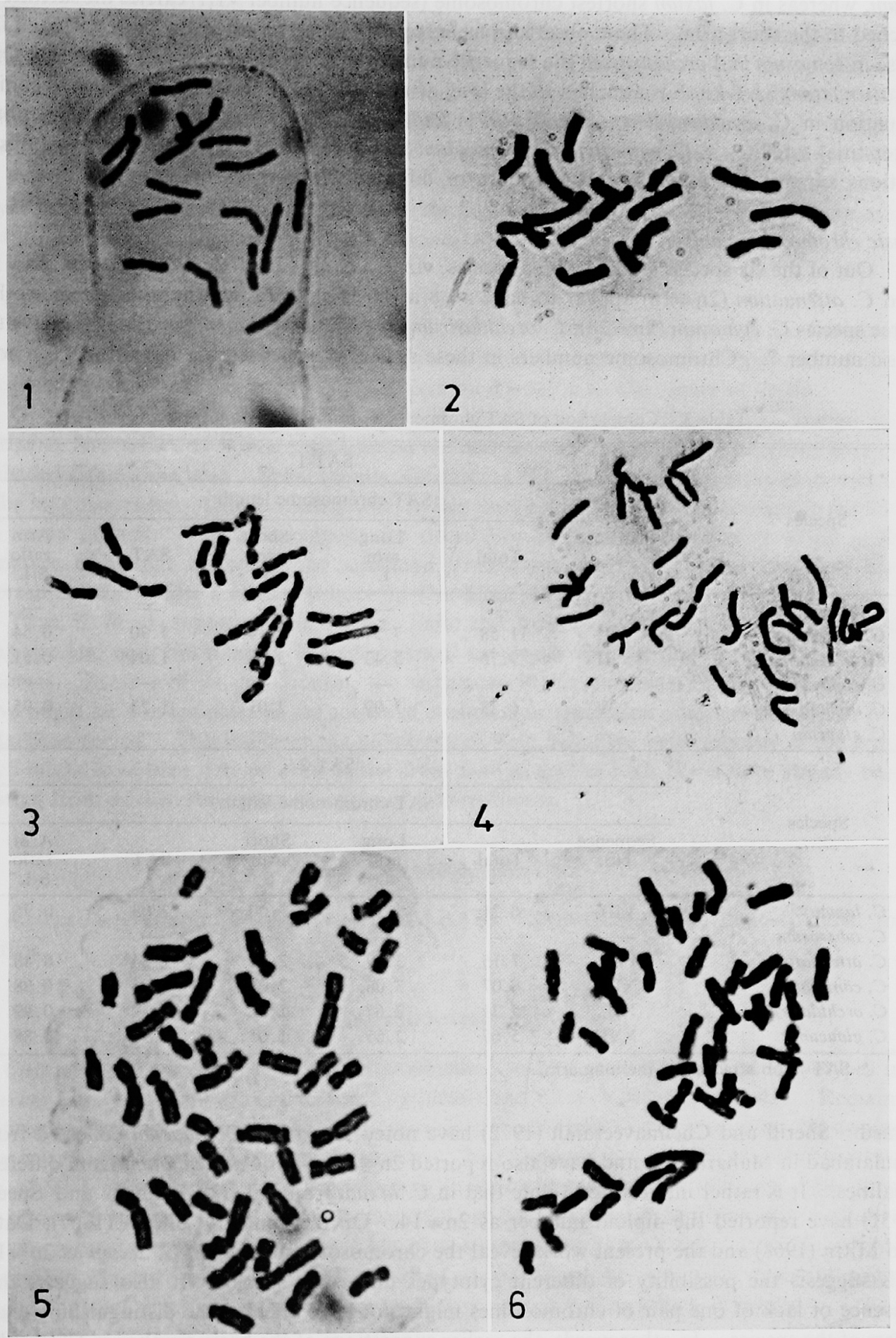

Plate 2. 1, somatic metaphase plate of $C$. laxum. $\times 1200.2$, somatic metaphase plate of $C$. tuberosum. $\times 1230.3$, somatic metaphase plate of $C$. attenuatum. $\times 1300.4$, somatic metaphase plate of $C$. comosum. $\times 1830.5$, somatic metaphase plate of $C$. glaucum. $\times 1660.6$, somatic metaphase plate of $C$. orchidastrum. $\times 1300$. 
atum, whereas in C. laxum shortest chromosome (sequence number VIII) carries the satellite attached to the short arm. These observations agree with those reported by Naik (1976). Likewise in comosum and orchidastrum the sequence number of the SAT chromosome is XII. Only in attenuatum SAT-knob is attached to the long arm (Plate 1). Sheriff (1971) observed similar situation in C. arundinaceum. Sheriff (1971) and Sheriff and Chennaveeraiah (1975) noted interstitial satellites in $C$. comosum, $C$. attenuatum and other hexaploid species. These observations support the possibility of existence of different biotypes or cytotypes.

\section{Basic chromosome number}

Out of the six species studied, three species, viz. C. laxum $(2 n=16), C$. tuberosum $(2 n=16)$ and $C$. attenuatum $(2 n=16)$ appear to have $x=8$ as basic chromosome number whereas other three species $C$. comosum $(2 \mathrm{n}=28)$, C. orchidastrum $(2 \mathrm{n}=42)$ and $C$. glaucum $(2 \mathrm{n}=42)$ have the basic number 7 . Chromosome numbers in these species reported earlier have thus been con-

Table 3. Comparison of SAT chromosomes in Chlorophytum species

\begin{tabular}{|c|c|c|c|c|c|c|}
\hline \multirow{3}{*}{ Species } & \multicolumn{6}{|c|}{ SAT-1 } \\
\hline & \multicolumn{6}{|c|}{ SAT chromosome length } \\
\hline & $\begin{array}{l}\text { Sequence } \\
\text { No. }\end{array}$ & Total & $\begin{array}{l}\text { Long } \\
\text { arm } \\
\text { L }\end{array}$ & $\begin{array}{l}\text { Short } \\
\text { arm } \\
\mathbf{S}\end{array}$ & SAT & $\begin{array}{l}\text { Arm } \\
\text { ratio } \\
\mathbf{S} / \mathbf{L}\end{array}$ \\
\hline C. laxum & - & - & - & - & - & - \\
\hline C. tuberosum & II & 11.58 & 7.54 & 2.14 & 1.90 & 0.54 \\
\hline C. attenuatum & II & 9.75 & 5.43 & 3.28 & $1.04^{*}$ & 0.51 \\
\hline C. comosum & - & - & - & - & - & - \\
\hline C. orchidastrum & $\mathrm{V}$ & 6.33 & 3.09 & 2.01 & 1.23 & 0.95 \\
\hline C. glaucum & - & - & - & - & 一 & 一 \\
\hline \multirow{3}{*}{ Species } & \multicolumn{6}{|c|}{ SAT-2 } \\
\hline & \multicolumn{6}{|c|}{ SAT chromosome length } \\
\hline & $\begin{array}{l}\text { Sequence } \\
\text { No. }\end{array}$ & Total & $\begin{array}{l}\text { Long } \\
\underset{\mathbf{L}}{\operatorname{arm}}\end{array}$ & $\begin{array}{l}\text { Short } \\
\text { arm } \\
\text { S }\end{array}$ & SAT & $\begin{array}{l}\text { Arm } \\
\text { ratio } \\
\text { S/L }\end{array}$ \\
\hline C. laxum & VIII & 6.21 & 3.18 & 1.00 & 2.03 & 0.95 \\
\hline C. tuberosum & - & - & - & - & - & - \\
\hline C. attenuatum & IV & 7.15 & 3.49 & 2.32 & $1.34^{*}$ & 0.48 \\
\hline C. comosum & XII & 6.07 & 3.06 & 2.06 & 0.95 & 0.98 \\
\hline C. orchidastrum & XII & 5.31 & 2.67 & 1.52 & 1.12 & 0.99 \\
\hline C. glaucum & XVII & 5.65 & 2.65 & 1.05 & 1.95 & 0.88 \\
\hline
\end{tabular}

* SAT-knob attached to the long arm.

firmed. Sheriff and Chennaveeraiah (1972) have noted $2 \mathrm{n}=16$ in C. glaucum collected from Daulatabad in Maharashtra and have also reported $2 n=42,84$ in C. attenuatum from different localities. It is rather interesting to note that in C. laxum from Liberia, Baldwin and Speese (1951) have reported the diploid number as $2 n=14$. On the contrary, Sheriff (1967), Datta and Mitra (1968) and the present work reveal the chromosome number in C. laxum as $2 \mathrm{n}=16$. This suggests the possibility of different cytotypes under the species. It also suggests that presence or lack of one pair of chromosomes might not have affected the distinguishing characters of the species. In other words, the earlier suggestions of the basic number in Chlorophytum species, which is to be secondary and might have been derived from $x=4$ (Naik 1977), have obvious importance. This is confirmed by the earlier reports of $2 n=8$ by Strasburger (1888) in C. sternbergianum Roxb. 


\section{Polyploidy in Chlorophytum}

Based on the chromosome numbers reported, the Chlorophytum species with $\mathrm{x}=7$ appear to be more in number as compared to those with $x=8$. This suggests that the species with $x=7$ have been relatively more adapted to climatic conditions, or the allotetraploids or polyploids of $x=7$ have developed the fixity and fluidity to withstand the climatic changes ultimately resulting in the survival of numerous species with $x=7$. On the contrary, species with $x=8$ are mostly restricted to the arid or semi-arid conditions. Thus, polyploidy appears to have played major role in the speciation process in the genus Chlorophytum. However, it is essential to study additional species to draw such conclusions.

\section{Geographical distribution of Chlorophytum species}

Chlorophytum species with $\mathrm{x}=8$ at diploid level and with $\mathrm{x}=7$ at diploid as also tetraploid or even higher levels are distributed from Aftrica to India and Australia. Majority of these species have been reported from Africa, indicating the same as the centre of origin.

Geographical distribution of Chlorophytum species in Africa, Madagascar, Indian subcontinent, Australia and Brazil suggests that the ancestral species might have existed over the undivided Gondwana land. Subsequently, Gondwana rifts and continental drifts have separated the landmasses into Africa, Madagascar, Indian part and South America alongwith the flora and fauna present. This also suggests the possibility of parallel evolution resulting in the formation of similar species in the separated landmasses. Similar observations have been reported on Gossypium and honey bees by Deodikar (1978).

Thus, $C$. laxum reported from Africa, India and Australia might be one of the ancestral living species, as it has more or less symmetrical karyotype with median or sub-median chromosomes. In spite of its distribution, the variations in chromosome numbers as discussed above might have taken place in the course of evolution or speciation processes during the post Cretaceous period. This indicates the possibility of $x=8$ being the basic number of the genus which might have been derived even earlier from $x=4$ as species with $2 n=8$ have already been reported from Africa, the centre of origin of Chlorophytum.

\section{Acknolwedgements}

Authors are grateful to the Director, M.A.C.S. Research Institute, Pune-4, India, for facilities.

\section{Summary/Abstract}

Chromosome morphology of six Chlorophytum species reveal symmetrical karyotypes in C. laxum $(2 \mathrm{n}=16)$ and asymmetrical in C. glaucum and C. orchidastrum $(2 \mathrm{n}=42)$. Remaining three species, viz. C. tuberosum, C. attenuatum $(2 \mathrm{n}=16)$ and $C$. comosum $(2 \mathrm{n}=28)$ appear to be intermediate in the karyotype symmetry. In $C$. attenuatum and $C$. orchidastrum two pairs of SAT chromosomes with variations in their sequence numbers and arm ratios have been observed, whereas in rest of the species only one SAT pair could be observed. Tentative basic chromosome number for the genus has been suggested to be $x=8$ and 7 , possibly derived as secondary number from $x=4$. Role of polyploidy in the speciation process, centre of origin and geographical distribution in relation to karyomorphology have been discussed.

\section{References}

Baldwin, J. T. and Speese, B. M. 1951. Cytogeography of Chlorophytum in Liberia. Amer. J. Bot. 38: 153-156. 
Datta, A. and Mitra, K. 1968. Karyotype analysis in Chlorophytum tuberosum Baker and C. laxum R. Br. Bull. Bot. Surv. India 10 (2): 228.

Deodikar, G. B. 1978. Possibilities of origin and diversification of angiosperms prior to continental drift. Recent Res. Geology 4: 473-481.

Engler, A. and Prantl, K. 1930. Die Natürlichen Pflanzenfamilien. 2. Auf. Leipzig, 1887-1909.

Hooker, J. D. 1892. Flora of British India, 6. London, L. Reeve

Mukherjee, N. 1975. Phytogeography and phylogeny of Chlorophytum Ker-Gawl. (Liliaceae). Bull. Bot. Soc. Soc. Bengal $29(1): 75-82$.

Naik, V. N. 1976. Chromosomal behaviour and evlolutionary trends in Chlorophytum (Liliaceae). Bot. J. Linn. Soc. 72: 45-50.

- 1977. Cytotaxonomic studies of six Indian species of Chlorophytum. Bot. J. Linn. Soc. 74: $297-308$.

Pahuja, A. N. and Kumar, V. 1969. Cytogeography of three species of Chlorophytum. Curr. Sci. 38: 469-471.

Riley, R. 1963. Wheat breeding and the behaviour of chromosomes. New Scientist 17: 698-700.

Santapau, H. and Fernandes, R. R. 1955. A new species of Chlorophytum from Salsette Island. Jour. Bomb. Nat. Hist. Soc. 52: 897-900.

Sears, E. R. 1958. The aneuploids of common wheat. Proc. 1st Int. Wheat Genet. Symp.: 221-229.

Sharma, A. K. and Mookherjea, A. 1955. Paradichlorobenzene and other chemicals in chromosome work. Stain Tech. $30: 1-7$.

Sheriff, A. 1967. Cytological and cytotaxonomic studies in certain members of Liliaceae. Ph. D. Thesis, Bangalore University.

- 1971. Karyomorphological studies in four hexaploid species of Chlorophytum. J. Cytol. and Genet. Congr. Suppl.: 26-32.

- and Chennaveeraiah, M. S. 1972. Karyomorphology of four diploid species of Chlorophytum. The Nucleus 15: $39-45$.

- and - 1975. Cytological studies in Chlorophytum attenuatum complex and cytotaxonomic considerations. Cytologia 40: 401-408.

Stebbins, G. L. 1958. Longevity, habit and release of genetic variability in higher plants. Cold Spr. Harb. Symp. Quant. Biol. 23: 365-378.

Strasburger, E. 1888. "Über Kern- und Zellteilung im Pflanzenreiche nebst einem Anhang über Befruchtung". Histol. Beitr. Heft. 1. Jena. 